\title{
Copper-Mediated Homologation of Alkynes to Allenes: The Crabbé Reaction
}

\section{Key words}

Crabbé reaction

homologation

allenes

copper catalysis
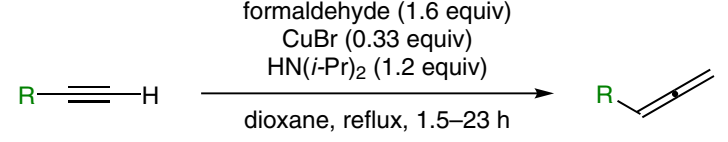

8 examples

up to $97 \%$ yield

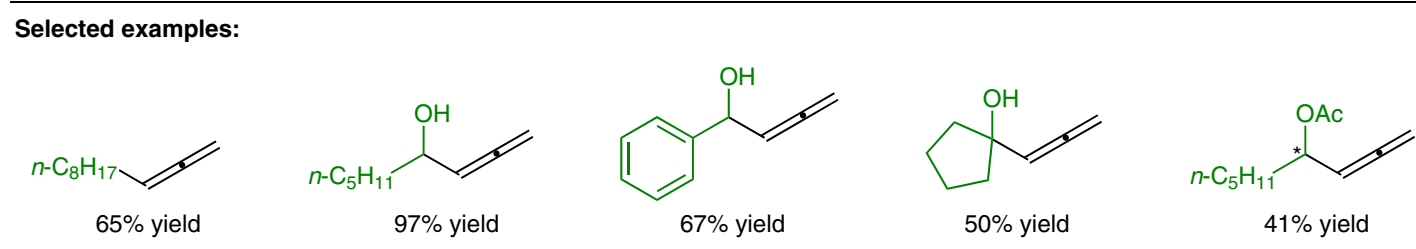

General mechanism:

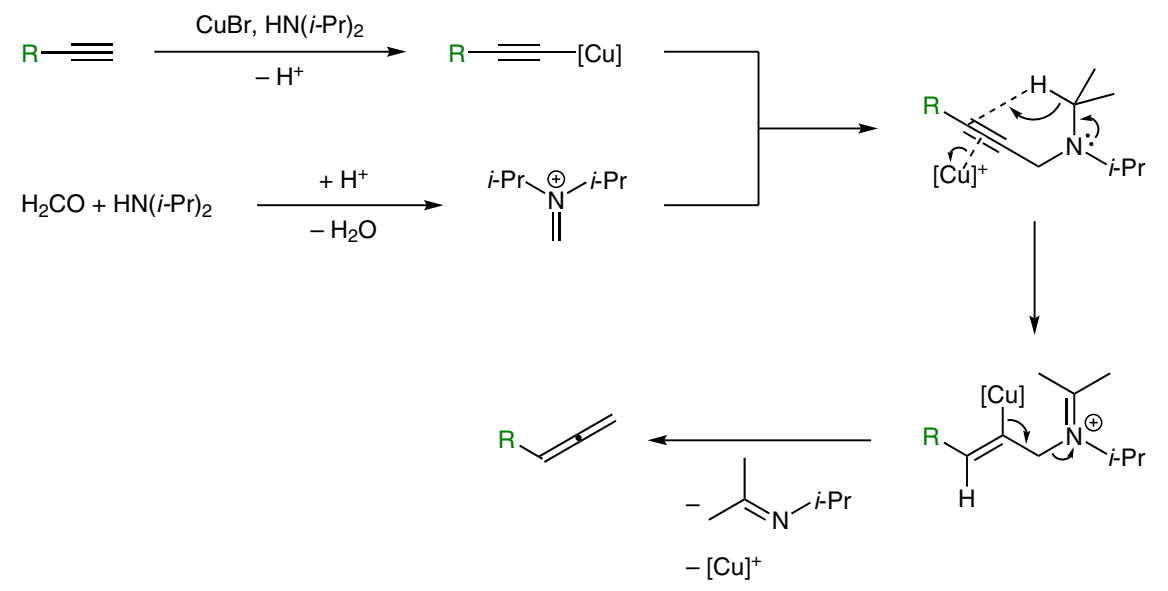

Significance: Crabbé and co-workers reported a copper-mediated homologation of terminal alkynes to allenes. Copper(I) bromide gave the best results among the metal salts that were investigated, and diisopropylamine (which serves multiple roles as a base, an iminium-forming carbonyl activator and a hydride donor) was found to be the optimal amine in terms of yields and reaction rates. The mechanism of the reaction was discussed in subsequent reports (see S. Searles et al. J. Chem. Soc., Perkin Trans. 1 1984, 747), and relies on the addition of a copper acetylide to an iminium ion, followed by a 1,5-hydride shift.
Comment: The Crabbé reaction remains a method of choice for the preparation of allenes. While the original conditions were limited to the synthesis of simple monosubstituted allenes, later contributions by Ma and others allowed for the preparation of multiply substituted allenes, as well as enantioselective variants (see Review below).

Review: X. Huang, S. Ma Acc. Chem. Res. 2019, 52, 1301-1312. 